\title{
Role of transposable elements in genomic rearrangement, evolution, gene regulation and epigenetics in primates
}

\author{
Hee-Eun Lee ${ }^{1,2 \dagger}$, Selvam Ayarpadikannan ${ }^{1 \dagger}$ and Heui-Soo Kim ${ }^{1,2 *}$ \\ ${ }^{1}$ Department of Biological Sciences, College of Natural Sciences, Pusan National University, \\ Busan 609-735, Republic of Korea \\ ${ }^{2}$ Genetic Engineering Institute, Pusan National University, Busan 609-735, Republic of Korea
}

(Received 23 January 2015, accepted 19 August 2015; J-STAGE Advance published date: 15 January 2016)

The Human Genome Project revealed that almost half of the human genome consists of transposable elements (TEs), which are also abundant in non-human primates. Various studies have confirmed the roles of different TE families in primate evolution. TEs such as endogenous retroviruses (ERVs), long terminal repeats (LTRs), long interspersed nuclear elements (LINEs) and short interspersed nuclear elements (SINEs) all have numerous effects on the primate genome, including genomic rearrangement, regulatory functions and epigenetic mechanisms. This review offers an overview of research on TEs, including our current understanding of their presence in modern primate lineages, their evolutionary origins, and their regulatory and modifying effects on primate as well as human genomes. The information provided here should be useful for the study of primate genomics.

Key words: epigenetics, evolution, genomic rearrangement, primates, transposable elements

\section{INTRODUCTION}

Transposable elements (TEs) are familiar as DNA sequences that have the ability to change their intragenomic location. The fraction of the genome that comprises TEs varies according to the species (Chenais et al., 2012). About $45 \%$ of the human genome is composed of TEs that have successfully replicated in the genome. Previously, TEs were considered as non-functional DNA sequences that parasitically maintained themselves in genomes, but we now know that TEs are extremely important to genome function and evolution (Hedges and Batzer, 2005; Feschotte, 2008). For example, various studies have reported that TEs provide binding sites for different transcription factors (TFs) (Wang et al., 2007; Bourque et al., 2008; Chuong et al., 2013; Sundaram et al., 2014). The insertion of a TE into a new location in the genome may result in alternative splicing (AS) of a particular transcript through various mechanisms, including exon skipping, intron retention and alternative donor or acceptor splice sites. Due to the increased protein diversity resulting from these processes, TE-derived AS events are thought to have played an important part in primate evolution and in hominid radiation (Hedges

Edited by Hidenori Nishihara

* Corresponding author. E-mail: khs307@pusan.ac.kr

$\dagger$ These authors contributed equally to this work.

DOI: http://doi.org/10.1266/ggs.15-00016 and Batzer, 2005). Technological advances in gene identification, sequencing and mapping have helped researchers to unravel the molecular mechanisms behind primate speciation and evolution (Laperriere et al., 2007; Bourque et al., 2008).

The genomic sequence of humans is almost identical to those of chimpanzees and bonobos (Prufer et al., 2012), but striking behavioral, physiological and morphological differences exist between the three hominids. An accumulating body of evidence has revealed that the regulation of gene expression, via elements such as TEs, is a major contributor to the differences between humans and our closest primate relatives (Sverdlov, 2000). Researchers have identified a number of TE families that may have major biological roles. For instance, all investigated vertebrate genomes contain endogenous retroviruses (ERVs) (Ijdo et al., 1991; Nickerson and Nelson, 1998). Retroviruses mostly infect somatic cells, but they may be transmitted to the next generation when they infect germ cells. In humans, human endogenous retroviruses (HERVs) and their associated long terminal repeats (LTRs) are believed to affect genome evolution by regulating nearby genes via transcriptional elements such as promoters. Therefore, they are likely to be important in primate speciation (Sverdlov, 2000). Another family of TEs is the short interspersed nuclear elements (SINEs), non-autonomous elements that cannot excise or insert themselves from or into the genome. Instead, their mobility depends on 
enzymes encoded by autonomous elements. Despite this, SINEs are pervasive throughout the mammalian genome (de Koning et al., 2011). Similar to HERVs, SINEs are also proposed to have regulatory functions. Long interspersed elements (LINEs) are non-LTR retrotransposons unlike HERVs, and the typical LINE-1 (L1) is $6 \mathrm{~kb}$ long and consists of two non-overlapping open reading frames (ORFs). The second ORF encodes an endonuclease and reverse transcriptase, and is transcribed by RNA polymerase II. These TEs (LTRs, SINEs and LINEs) have a copy-and-paste transposition mechanism and are classified as Class I (Fig. 1). On the other hand, DNA transposons change their position by cut-and-paste, and are classified as Class II. Some DNA transposons bind to specific DNA sequence targets, and these target sites can participate in genomic rearrangement, which plays an important role in evolution.

Beyond influencing gene expression, TEs can also affect the genome in the following ways: (a) increasing genome size through TE amplification (Bailey and Eichler, 2006; Ichiyanagi, 2013); (b) causing loci rearrangements through TE insertions (Sen et al., 2006); and (c) creating greater genetic (and phenotypic) diversity, thereby facilitating genetic adaptation to environmental changes, and so on (Herniou et al., 1998). Researchers have proposed several hypotheses to unify the multiple ways in which TEs can modify the genome and influence evolutionary trajectories. One example is the TE-thrust hypothesis (Oliver and Greene, 2011). In this framework, TEs facilitate the appearance of new traits by actively or passively engineering the coding/regulatory regions of the genome. Several TEs appear to have been especially influential in primate evolution. Besides the aforementioned ERVs, which have amplified and altered primate genomes, primate-specific Alu SINEs dominate TE sequences in simians and are frequently found in gene-rich regions. In association with the autonomous L1, Alus are correlated with primate lineage divergence and may have played a crucial role.

For the past two decades, numerous studies have investigated TEs and their roles in the genome, resulting in attempts to unify the explosion of data by means of frameworks such as the TE-thrust hypothesis. However, the variety of TEs and their effects on the genomes of different organisms can be bewildering. Therefore, in this review, we categorize the various impacts of TEs on the primate genome, specifically, to create an organized and updated resource to stimulate the interest of researchers in the intersection of these two subjects. We hope this review will be useful for furthering genome-wide TE assays and studies of TE function in the primate genome.

\section{HALF OF THE PRIMATE GENOME CONSISTS OF TRANSPOSABLE ELEMENTS}

The availability of whole-genome sequencing data allows us to make comparative analyses across taxa. TEs comprise as much as 30-50\% of mammalian genomes (http://www.repeatmasker.org). In particular, approximately $50 \%$ of primate genomes consist of TEs (Fig. 2). Primates are divided into prosimians and simians, and the proportion of TEs is lower in prosimians than in simians. Primate-specific Alu elements appear to have been inserted after the primate radiation approximately 100 million years ago (Mya), and a major burst of Alu amplification was estimated to have occurred from 50 to

\section{Types of retroelement}

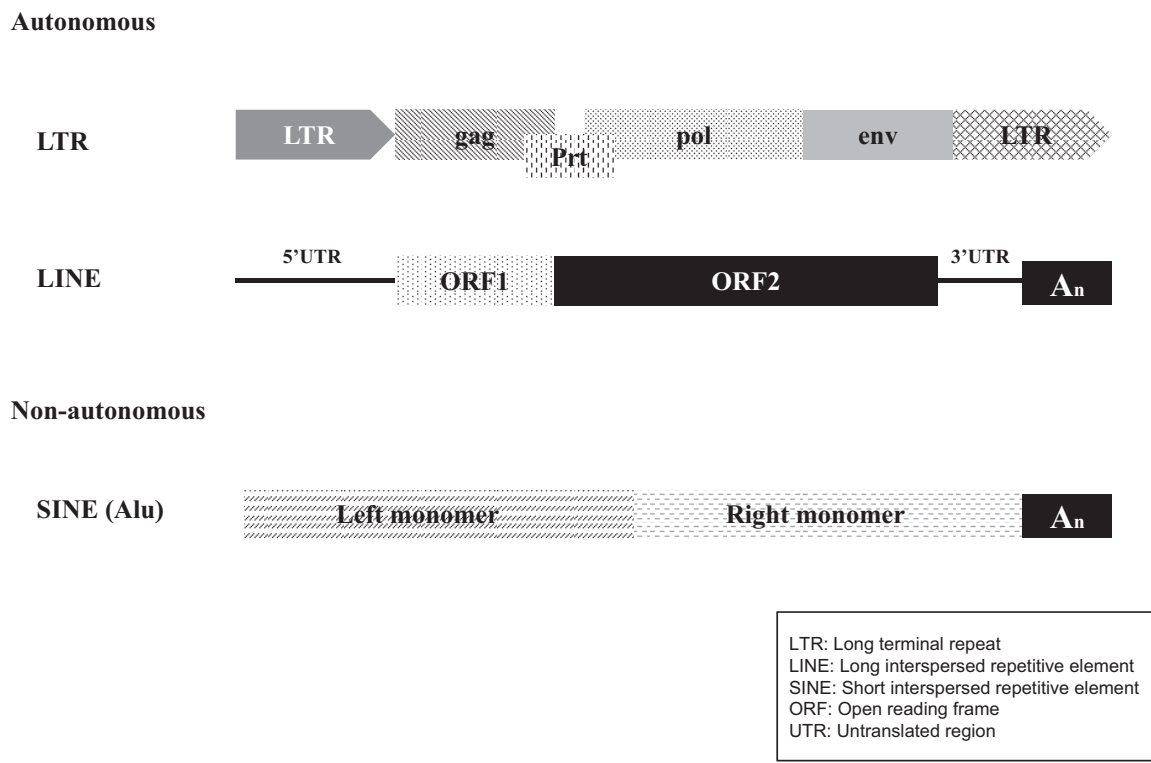

Fig. 1. Schematic structures of types of retroelements. 


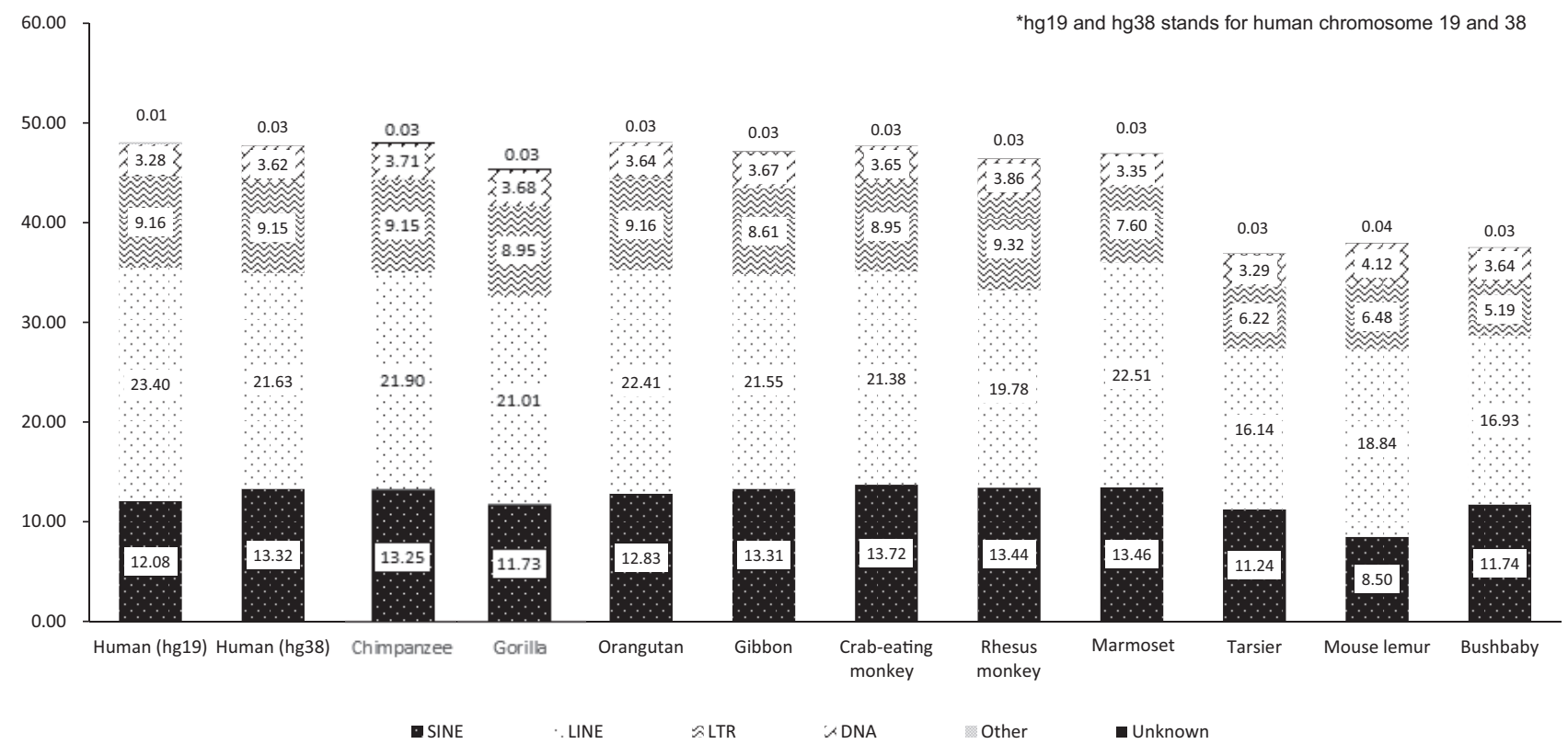

Fig. 2. Proportion of TEs in the genomes of primates. This graph presents percentages (y-axis) of the four major TE classifications within each genome sequence.

25 Mya (Shen et al., 1991). In a comparison of Alu frequency across multiple primate taxa, the Mouse Lemur Genome Project found that the genomes of prosimian lemurs contain the lowest Alu density, whereas the genomes of crab-eating macaques contain the highest Alu density (Fig. 2) (Liu et al., 2009; Ohshima et al., 2003). In addition, the non-autonomous element SVA (named after its three components: SINE-R, VNTR and $\mathrm{Alu}$ ) is a recent TE that is frequently detected in hominoid genomes (Wang et al., 2005). Finally, a newly identified TE, LAVA (L1NE5, AluSz6 and SVA_A) appears to be unique to the gibbon genome (Carbone et al., 2012). Taken together, these data indicate that TEs have inserted continuously throughout primate evolution. Thus, these specific TEs are likely to have expanded the primate genome and acquired novel regulatory functions over time.

Of note, the proportion of TEs is higher in more recent primate taxa. Specifically, a greater proportion of SINEs exists in simians compared to prosimians, implying that the simian genome has evolved, through TE-thrust, to use Alu elements in various regulatory functions. LINEs and SINEs occupy together about $60 \%$ of total TE sequences in all investigated species of primate, suggesting their evolutionary importance across simians and prosimians. Indeed, these two elements can induce genomic rearrangement (Frederick et al., 2000; Han et al., 2005), which may be a primary mechanism behind the lineage- and species-specific genomic structure we see today (Oliver and Greene, 2009). In sum, such comparative analyses, made possible by whole-genome sequencing technology, reveal a great deal about the role of TEs in primate speciation, radiation and evolution (Konkel et al., 2010). As the number of sequenced primate genomes increases, we should be able to improve our understanding of primate evolutionary history at the genomic level.

\section{ROLE OF TRANSPOSABLE ELEMENTS IN GENOMIC REARRANGEMENTS IN PRIMATES}

Genomic rearrangement due to insertions, deletions or disruption can have substantial negative and positive consequences, from generating genetic disorders to creating enough genetic diversity to facilitate adaptive radiations (Fig. 3). Dosage-sensitive genes are particularly affected by such genomic processes. Among primates, gibbons (family Hylobatidae) appear to have more frequent chromosomal rearrangements than most other mammals (Kehrer-Sawatzki and Cooper, 2008). A recent study has defined the rearrangements that have occurred in the Symphalangus $(2 \mathrm{n}=50)$ and Hoolock $(2 \mathrm{n}=38)$ karyomorphs (Capozzi et al., 2012). The results provided a comprehensive insight into the evolutionary origins of chromosomal rearrangements involved in transforming the gibbon genome. Analyses of human-gibbon synteny breakpoints underscored the role of TEs in segmental duplications (SDs), which eventually resulted in chromosomal rearrangements (Capozzi et al., 2012).

Other primate studies have also made associations between SDs and genome rearrangements in primate evolution, human genomic structural variation and disease susceptibility (Emanuel and Shaikh, 2001; Bailey and Eichler, 2006). In addition, studies have revealed that primate genome rearrangement events were associated 

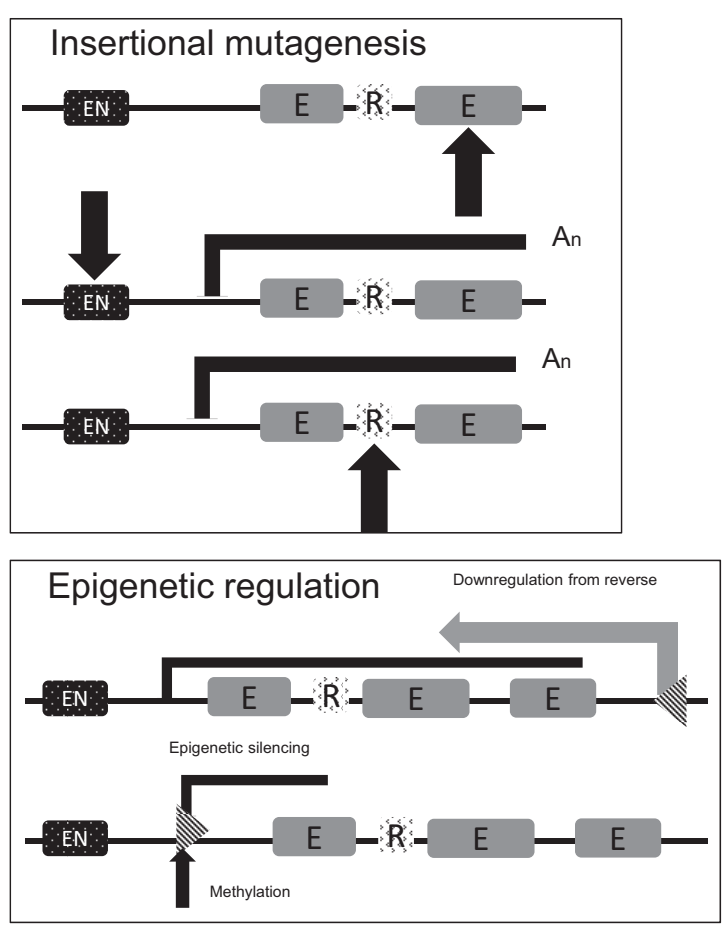

EN: Enhancer R: Repressor E: Exon Nim: Promoter

Insertion

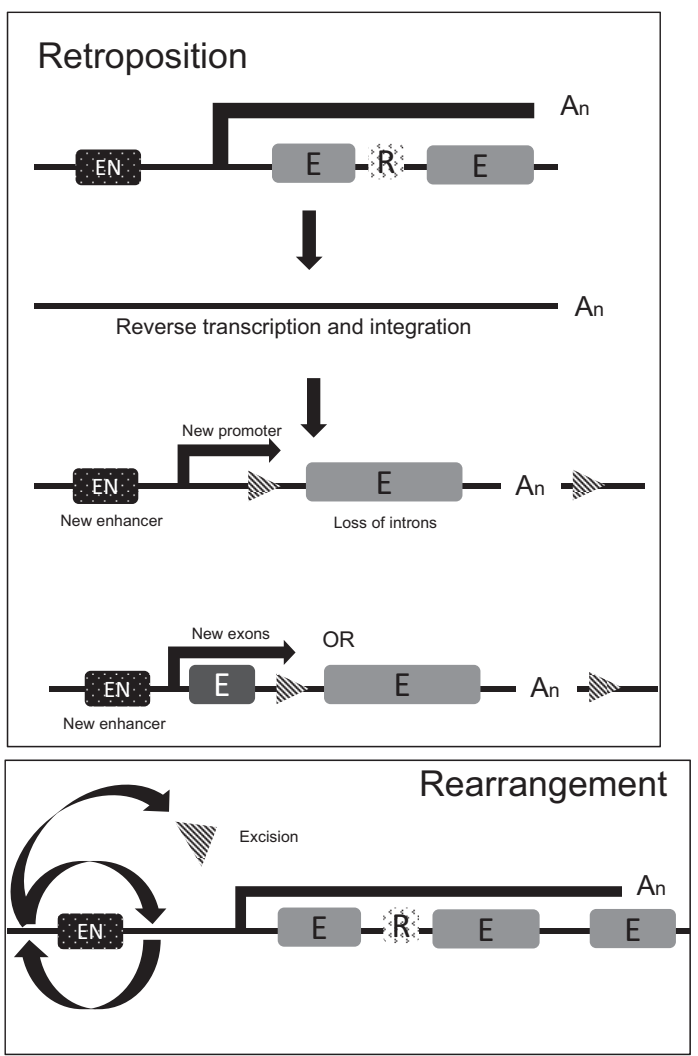

Fig. 3. Graphical summary of the functions of TEs in genomic rearrangement, gene regulation and epigenetics. with Alu elements in a process called Alu recombinationmediated deletion (ARMD). Human-specific ARMD events were detected in 492 cases, and deleted genomic sequences of $400 \mathrm{~kb}$ were uncovered in the human lineage (Sen et al., 2006). That study also detected 663 cases of chimpanzee-specific ARMD events, as well as $771 \mathrm{~kb}$ of deleted genomic sequences. Thus, SDs and Alus appear to have greatly modified ape genomic sequences, contributing to the lineage-specific changes in host genomes that accompany speciation.

Given the close association between Alus and L1s in primates, it is unsurprising that Kim and colleagues found that chromosomal rearrangements were associated with L1 repeats (Kim et al., 2008). Another study also identified 73 human-specific L1-associated deletion events that occurred subsequent to the divergence of the human and chimpanzee lineages (Han et al., 2008). However, L1s are not only associated with primate evolutionary divergence. A study including various mammalian genomes (chimpanzee, human, rhesus macaque, dog, rat and mouse) discovered that pairs of $\mathrm{L} 1$ repeats were over-represented in the breakpoints of ancestral inversions across all of the studied lineages (Zhao and Bourque, 2009), suggesting ancient origins for L1s.

Advanced methods that yield much larger amounts of data have served to confirm the widespread nature of genomic rearrangements and resulting structural variation. For instance, Korbel et al. (2007) used a highthroughput, paired-end sequencing strategy to determine genome rearrangement events in two human individuals. They observed that approximately $14 \%$ of structural variation events in humans were genome rearrangements, and they were likely to be non-allelic homologous recombination-associated. Due to their ubiquity, genomic rearrangement events should prove valuable in future studies on primate evolution, particularly in terms of understanding how it relates to evolution in other mammalian lineages.

\section{TRANSPOSABLE ELEMENTS ARE THE MAJOR SOURCE OF PRIMATE-SPECIFIC REGULATORY SEQUENCES}

Various studies have reported on the numerous regulatory roles of TEs (Table 1). In particular, TE-derived sequences are now recognized to provide binding sites for various mammalian TFs (Jacques et al., 2013). However, most studies that examined the role of TEs in binding sites have focused on only a few TFs and cell types. To examine the impact of TEs on the human chromatin landscape, and using the Encyclopedia of DNA Elements (ENCODE) database, Jacques and colleagues have recently identified the locations of active regulatory elements in more than 40 human cell types. Their results 
Table 1. Gene regulatory roles of transposable elements in primates

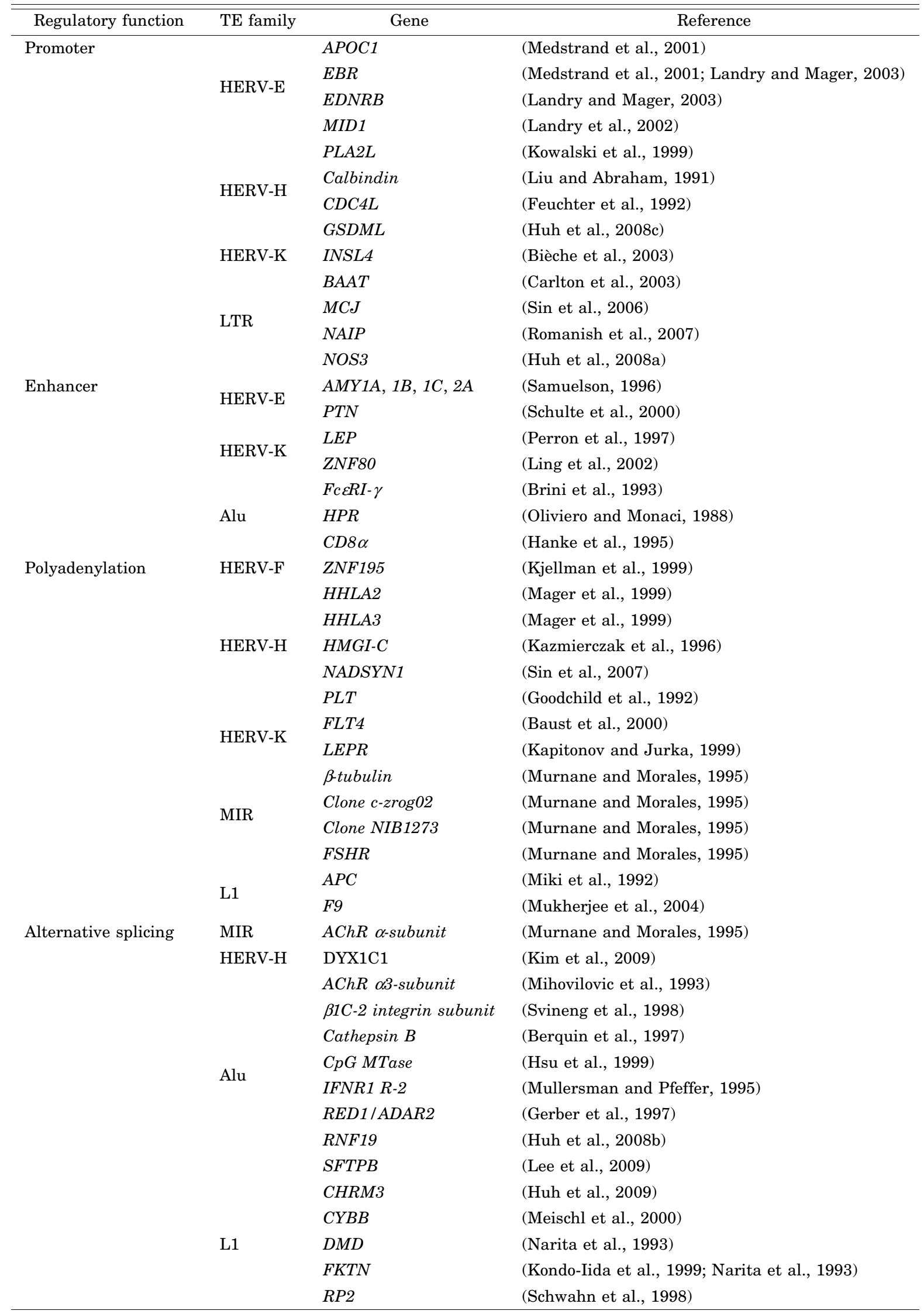


demonstrated that TE-derived sequences have contributed thousands of novel regulatory elements to the primate lineage and reshaped the human transcriptional landscape (Jacques et al., 2013). In addition, TEs may have contributed about half of the open chromatin regions in the human genome, as well as the majority of primatespecific elements. Jacques et al. (2013) predicted about 2,150 TF-repeat subfamily associations, and their findings may provide insights into the functions of some of the TE-derived loci that had already been implicated as regulatory elements.

Specific TEs known to influence regulatory elements in primates are LTR/ERV repeats. Previous studies have shown that LTR/ERV repeats contribute a portion of cell type-specific, accessible chromatin regions in embryonic cell lines. ERV elements appear to play a key role in rewiring the transcription network of human embryonic stem cells (Kunarso et al., 2010; Lynch et al., 2011; Chuong et al., 2013) and also of induced pluripotent stem cells (Fort et al., 2014). HERV-H was found to be an essential regulatory element (Ohnuki et al., 2014). Additionally, TE-derived transcripts, such as lincRNAs (Kelley and Rinn, 2012), are tissue-specific (Faulkner et al., 2009). Thus, these reports have demonstrated that ERVs have affected the primate transcriptome and contributed to primate evolution.

Numerous studies have identified the involvement of TEs in gene regulatory networks though the rearrangement of genes, regulatory elements and genomic structures (for reviews, see Bourque, 2009; Konkel et al., 2010; de Souza et al., 2013). Some TEs are quite ancient, such as a SINE-derived enhancer that has remained in the mammalian genome for 170 million years (Santangelo et al., 2007). These SINE-derived elements may play critical roles in the genome (Nishihara et al., 2006); for instance, one has been implicated as an enhancer for the ISL-1 gene (insulin gene enhancer protein) (Bejerano et al., 2006). Another study demonstrated that a highly conserved mammalian SINE also functions as an enhancer of FGF8 in two regions of the developing forebrain (Sasaki et al., 2008).

Besides being enhancers, TEs are implicated in other aspects of genomic function and have been actively preserved by selection. Gombart et al. (2009) reported that a vitamin $\mathrm{D}$ receptor binding element in the cAMP gene originated from AluSx in an ancestral lineage to primates, and has remained under purifying selection for the last 55-60 million years. Additionally, it was suggested that TE transcription is a developmental strategy to establish functionally distinct domains within mammalian genomes, which then control gene activation (Lunyak et al., 2007; Lynch et al., 2011; Schmidt et al., 2012). Approximately $25 \%$ of promoter regions in the human genome contain TE-derived sequences, which function as transcription initiation sites (Jordan et al., 2003).
Similarly, a large fraction of functional genomic sites consists of primate-specific TEs derived from ERV1 (Wang et al., 2007). In addition, Alu and L2 elements contain TF binding motifs that are expected to be bound by TFs in vivo (Johnson et al., 2006; Polak and Domany, 2006; Laperriere et al., 2007). Next, about $32 \%$ of the binding sites detected in vivo for five TFs (ESR1, TP53, POU5F1, SOX2 and CTCF) are derived from multiple TE families (Bourque et al., 2008). Moreover, these repeat-associated binding sites (RABS) correlate with expansions of ciselements throughout mammalian phylogeny, and are enriched in the proximity of regulated genes. Together, these findings provide evidence for the functional significance of RABS.

The evolution of regulatory elements is a universal feature of eukaryotic genomes (Dermitzakis and Clark, 2002; Moses et al., 2006; Borneman et al., 2007; Odom et al., 2007; Johnson et al., 2009). The studies we have described confirm the role of TEs in shaping mammalian regulatory networks, via alteration of the supply of regulatory sequences to the host genome. The development of promising techniques has increased the feasibility of studies on the regulatory roles of TEs. Databases such as ENCODE are also invaluable in helping us to understand what portions of the genome are transcribed and functionally active under different conditions. Thus, further delineating primate-specific TE insertion patterns should allow us to understand the functional effects of TEs on primate evolution.

\section{ASSOCIATION OF TRANSPOSABLE ELEMENTS WITH EPIGENETIC MECHANISMS IN PRIMATES}

Networks of epigenetic mechanisms have evolved in eukaryotes to regulate the expression and activity of TEs. TEs have served as building blocks for epigenetic phenomena, due to their ability to recruit silencing machinery (Slotkin and Martienssen, 2007). Recent studies have demonstrated that tandem repeats in various TEs can be marked by methylated histones. One example is the H3K9 (lysine 9 trimethylated histone H3) trimethylation at Alu repeats in human cells, which suppresses Alu element transposition (Kondo and Issa, 2003). Another example is the association between histone methylation and repetitive DNA (Martens et al., 2005), where researchers found that TEs had variable histone methylation levels between different types of embryonic stem cells. Although Martens et al. (2005) did not find H3K9 enrichment, a later study revealed that mouse LTR elements were enriched for other repressive histone marks (Mikkelsen et al., 2007).

Numerous other studies have found that methylation of cytosine at $\mathrm{CpG}$ sites in the mammalian genome is a key epigenetic modification, which results in the repression of genes, LINEs and LTR elements (Walsh et al., 1998; Bird, 
2002; Bourc'his and Bestor, 2004; Tsumura et al., 2006). In human somatic tissues, 25 highly methylated CpG sites surround the Alu promoter of Pol III (HellmannBlumberg et al., 1993; Kochanek et al., 1993; Xie et al., 2009). In addition, studies have demonstrated that this methylation inhibits Pol III transcription of Alu and tRNA genes (Besser et al., 1990; Englander et al., 1993; Kochanek et al., 1993; Liu and Schmid, 1993). Methylation may interfere with TFIIIC binding to A and B boxes, which then prevents the attachment of Pol III to the promoter. Additionally, the H3K9me3 that marks Alu elements (Kondo and Issa, 2003) was confirmed to be important for heterochromatin formation and repression of LTR elements (Matsui et al., 2010; Karimi et al., 2011). As further confirmation, ChIP assay results revealed that when Alu elements were not bound by Pol III in cultured cells, they were transcriptionally silenced (Oler et al., 2010).

The insertion of retrotransposons into the germline of host cells allows them to be transmitted to the next generation, which can have potentially negative consequences for the host. Therefore, DNA methylation plays crucial roles in LINE and LTR repression in these cells (Reik et al., 2001; Sasaki and Matsui, 2008). During the insertion of retrotransposons, developing germ cells produce a class of small RNAs (24 to 33 nucleotides long) called piwi-interacting RNA (piRNA) (Siomi et al., 2011; Chuma and Nakano, 2013). In addition, embryonic stem cells require the H3K9 trimethylation enzyme Setdb1 (Eset) for the repression of ERVs in brain and germ cells (Tan et al., 2012; Liu et al., 2014). Moreover, Alu and
SVA have been reported to be regulated by KRAB-zinc finger proteins, and this regulation is related to H3K9me3 (Jacobs et al., 2014). Several studies have revealed that most piRNAs are derived from retrotransposons, and the elimination of piRNAs from male germ cells by mutations in Mili, Miwi2 or MitoPLD resulted in LINE overexpression and hypomethylation (Aravin et al., 2007; Kuramochi-Miyagawa et al., 2008; Watanabe et al., 2011). Thus, piRNAs offer a germline defense system against retrotransposons in animals. Since LINEs and other TEs can have deleterious effects on the organism due to their ability to substantially modify the genome, appropriate repression of TEs is critical for proper growth and development.

\section{THE MAJOR ROLE OF TRANSPOSABLE ELEMENTS IN PRIMATE EVOLUTION}

After decades of research, we now know that what had previously been categorized as "junk DNA" (non-coding regions of the genome) is actually rich in elements of functional significance, pseudogenes, retropseudogenes, DNA transposons, retrotransposons and ERVs (Hedges and Batzer, 2005). Furthermore, comparative genomic analyses have shown that various non-coding sequence motifs are conserved in placental mammals and monotremes (Dermitzakis et al., 2003, 2005), implying that they must have sufficient biological importance to be retained across distantly related taxa.

The Alu lineage originated shortly after the origin of primates and therefore occurs exclusively in primates (Fig. 4).

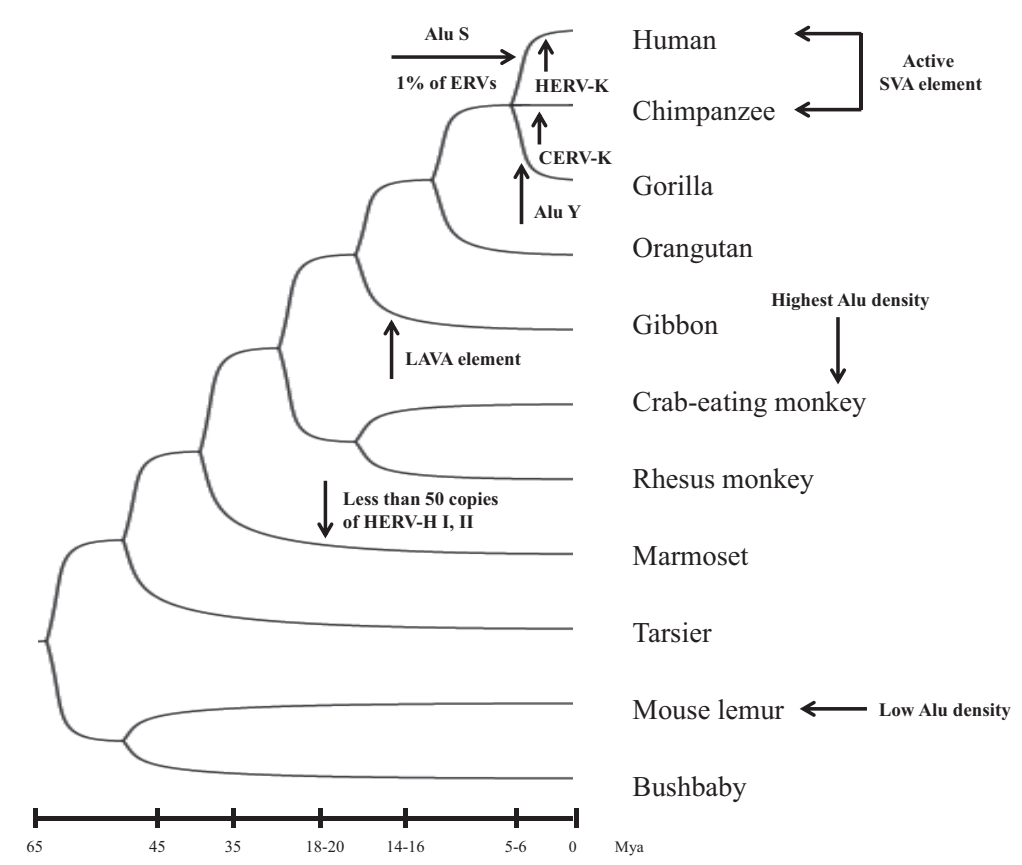

Fig. 4. Phylogenetic tree for primate evolution. The tree provides approximate times of TE insertions in primate evolution. 
It is found in all simian and prosimian genomes examined to date (Ullu and Tschudi, 1984). The Alu family is believed to have originated from 7SLRNA (involved in the protein signal recognition complex) (Ullu and Tschudi, 1984). In contrast, most of the other SINEs have arisen from tRNA genes (Okada, 1991).

We now know that Alus depend on the transposition machinery of L1 elements to modify the genome (Dewannieux et al., 2003). Remnants of ancient modifications by Alus and L1s can still be found in primate genomes. One significant evolutionary event was the formation of dimeric Alus (Zietkiewicz et al., 1998), which is believed to have occurred prior to the major expansion of Alu subfamilies 30-40 Mya (Hedges and Batzer, 2005; Lee et al., 2015). On the other hand, primate L1 sequences are derived from ancestral mammalian LINEs (Malik and Eickbush, 2001). Interestingly, whereas the human genome contains numerous full-length active elements, it also has numerous defective elements due to truncation of the 5' region (Myers et al., 2002).

Apart from the L1 and Alu families that constitute the majority of primate-specific TEs, DNA transposons, SINE-R, LTR retrotransposons, ERVs and SVAs have also left their marks on primate genomes (Smit and Riggs, 1996). The "cut-and-paste" DNA transposons were active about 80-90 Mya. For example, a DNA transposon named Tigger gave rise to numerous, miniature inverted repeat transposable element sequences in the genome of ancestral primates (Smit and Riggs, 1996). Next, ERVs comprise nearly $1 \%$ of the human genome (Sverdlov, 2000) and are the remnants of ancient germline retroviral infections (Fig. 4). The integration of ERVs into the germline allows them to be inherited in a Mendelian fashion. Moreover, ERV insertions may alter the expression of nearby genes. Yet another TE is the relatively new SVA element (Fig. 4), which remains active in humans and chimpanzees, contributing to both genetic diversity and human disease (Ostertag et al., 2003; Wang et al., 2005). Finally, unique to the gibbons, the LAVA element has been highly influential in modifying the gibbon genome with large numbers of chromosomal rearrangements (Fig. 4), which likely explains the frequent speciation in that family (Carbone et al., 2012).

In human evolution, HERV elements and their associated LTRs have played a major role, affecting genome function through the expression of retroviral genes, genome rearrangement or the regulation of nearby genes (Leib-Mosch and Seifarth, 1995; Lower et al., 1996; Britten, 1997; Patience et al., 1997; Harris, 1998; Sverdlov, 1998). Abundant solitary LTRs comprise a variety of transcription regulatory elements, such as promoters, enhancers, hormone-responsive elements and polyadenylation signals (Sverdlov, 2000). Phylogenetic analyses indicate that HERVs entered the primate genome early in primate evolution, although the exact time is unclear (Fig.
4). Most of the HERV families were amplified in the germline after the separation of Old and New World monkeys (around 30-45 Mya). Additionally, some HERV-related sequences are reported to be present in New World monkeys, and hence their age is over 45 million years (Lebedev et al., 1995; Simpson et al., 1996). On the other hand, based on sequence divergence data, some HERVs may have entered the primate genome before prosimians and New World monkeys diverged (60 Mya) (Leib-Mosch and Seifarth, 1995; Anderssen et al., 1997; Medstrand and Mager, 1998).

Perhaps because of this variation, the rate of amplification is variable among different HERV families. Mager and Freeman (1995) reported that the genomes of New World monkeys contain less than 50 copies of HERV-H I and II elements (Fig. 4), but their number increased to 900 truncated copies and 50-100 full-length forms during primate evolution. Also, HERV-K and CERV-K elements appeared approximately 5 Mya (Romano et al., 2006). Altogether, HERV element insertions have contributed to the transcriptional regulation of neighboring genes by supplying new promoters, and played multiple roles to affect genomic plasticity during primate evolution (Kim, 2012).

\section{CONCLUSIONS AND FUTURE PERSPECTIVES}

Recent technical advances in genomics have resulted in the rapid progress of genome-wide studies. The results of such research have revealed that TEs are abundant in the genomes of many mammals, including primates. Genomic modification due to TEs is of particular relevance in primates, as they give us insight into human evolution. Therefore, in this review, we have given an overview of major TE-associated genomic events in the primate lineage. Although we have learned a great deal since the discovery of transposable elements by Barbara McClintock, continuous improvements to our genetic tools should result in even stronger, more detailed studies on how TEs facilitate primate evolution.

This research was supported by the Cooperative Research Program of the Primate Research Institute, Kyoto University.

\section{REFERENCES}

Anderssen, S., Sjottem, E., Svineng, G., and Johansen, T. (1997) Comparative analyses of LTRs of the ERV-H family of primate-specific retrovirus-like elements isolated from marmoset, African green monkey, and man. Virology 234, 1430.

Aravin, A. A., Sachidanandam, R., Girard, A., Fejes-Toth, K., and Hannon, G. J. (2007) Developmentally regulated piRNA clusters implicate MILI in transposon control. Science 316, 744-747.

Bailey, J. A., and Eichler, E. E. (2006) Primate segmental duplications: crucibles of evolution, diversity and disease. Nat. 
Rev. Genet. 7, 552-564, 898-898(Erratum).

Baust, C., Seifarth, W., Germaier, H., Hehlmann, R., and LeibMosch, C. (2000) HERV-K-T47D-related long terminal repeats mediate polyadenylation of cellular transcripts. Genomics 66, 98-103.

Bejerano, G., Lowe, C. B., Ahituv, N., King, B., Siepel, A., Salama, S. R., Rubin, E. M., Kent, W. J., and Haussler, D. (2006) A distal enhancer and an ultraconserved exon are derived from a novel retroposon. Nature 441, 87-90.

Berquin, I. M., Ahram, M., and Sloane, B. F. (1997) Exon 2 of human cathepsin B derives from an Alu element. FEBS Lett. 419, 121-123.

Besser, D., Gotz, F., Schulze-Forster, K., Wagner, H., Kroger, H., and Simon, D. (1990) DNA methylation inhibits transcription by RNA polymerase III of a tRNA gene, but not of a $5 \mathrm{~S}$ rRNA gene. FEBS Lett. 269, 358-362.

Bièche, I., Laurent, A., Laurendeau, I., Duret, L., Giovangrandi, Y., Frendo, J.-L., Olivi, M., Fausser, J.-L., Evain-Brion, D., and Vidaud, M. (2003) Placenta-specific INSL4 expression is mediated by a human endogenous retrovirus element. Biol. Reprod. 68, 1422-1429.

Bird, A. (2002) DNA methylation patterns and epigenetic memory. Genes Dev. 16, 6-21.

Borneman, A. R., Gianoulis, T. A., Zhang, Z. D. D., Yu, H. Y., Rozowsky, J., Seringhaus, M. R., Wang, L. Y., Gerstein, M., and Snyder, M. (2007) Divergence of transcription factor binding sites across related yeast species. Science 317, 815-819.

Bourc'his, D., and Bestor, T. H. (2004) Meiotic catastrophe and retrotransposon reactivation in male germ cells lacking Dnmt3L. Nature 431, 96-99.

Bourque, G. (2009) Transposable elements in gene regulation and in the evolution of vertebrate genomes. Curr. Opin. Genet. Dev. 19, 607-612.

Bourque, G., Leong, B., Vega, V. B., Chen, X., Lee, Y. L., Srinivasan, K. G., Chew, J. L., Ruan, Y., Wei, C. L., Ng, H. H., et al. (2008) Evolution of the mammalian transcription factor binding repertoire via transposable elements. Genome Res. 18, 1752-1762.

Brini, A. T., Lee, G. M., and Kinet, J. P. (1993) Involvement of Alu sequences in the cell-specific regulation of transcription of the $\gamma$-chain of Fc and T-Cell receptors. J. Biol. Chem. 268, 1355-1361.

Britten, R. J. (1997) Mobile elements inserted in the distant past have taken on important functions. Gene 205, 177-182.

Capozzi, O., Carbone, L., Stanyon, R. R., Marra, A., Yang, F. T., Whelan, C. W., de Jong, P. J., Rocchi, M., and Archidiacono, N. (2012) A comprehensive molecular cytogenetic analysis of chromosome rearrangements in gibbons. Genome Res. 22, 2520-2528.

Carbone, L., Harris, R. A., Mootnick, A. R., Milosavljevic, A., Martin, D. I., Rocchi, M., Capozzi, O., Archidiacono, N., Konkel, M. K., Walker, J. A., et al. (2012) Centromere remodeling in Hoolock leuconedys (Hylobatidae) by a new transposable element unique to the gibbons. Genome Biol. Evol. 4, 760-770.

Carlton, V. E. H., Harris, B. Z., Puffenberger, E. G., Batta, A. K., Knisely, A. S., Robinson, D. L., Strauss, K. A., Schneider, B. L., Lim, W. A., Salen, G., et al. (2003) Complex inheritance of familial hypercholanemia with associated mutations in TJP2 and BAAT. Nat. Genet. 34, 91-96.

Chenais, B., Caruso, A., Hiard, S., and Casse, N. (2012) The impact of transposable elements on eukaryotic genomes: From genome size increase to genetic adaptation to stressful environments. Gene 509, 7-15.
Chuma, S., and Nakano, T. (2013) piRNA and spermatogenesis in mice. Philos. Trans. R. Soc. Lond. B Biol. Sci. 368, 20110338.

Chuong, E. B., Rumi, M. A. K., Soares, M. J., and Baker, J. C. (2013) Endogenous retroviruses function as species-specific enhancer elements in the placenta. Nat. Genet. 45, 325329.

de Koning, A. P. J., Gu, W. J., Castoe, T. A., Batzer, M. A., and Pollock, D. D. (2011) Repetitive elements may comprise over two-thirds of the human genome. PLoS Genet. 7, e1002384.

de Souza, F. S. J., Franchini, L. F., and Rubinstein, M. (2013) Exaptation of transposable elements into novel cis-regulatory elements: is the evidence always strong? Mol. Biol. Evol. 30, 1239-1251.

Dermitzakis, E. T., and Clark, A. G. (2002) Evolution of transcription factor binding sites in mammalian gene regulatory regions: Conservation and turnover. Mol. Biol. Evol. 19, 1114-1121.

Dermitzakis, E. T., Reymond, A., Scamuffa, N., Ucla, C., Kirkness, E., Rossier, C., and Antonarakis, S. E. (2003) Evolutionary discrimination of mammalian conserved non-genic sequences (CNGs). Science 302, 1033-1035.

Dermitzakis, E. T., Reymond, A., and Antonarakis, S. E. (2005) Conserved non-genic sequences - an unexpected feature of mammalian genomes. Nat. Rev. Genet. 6, 151-157.

Dewannieux, M., Esnault, C., and Heidmann, T. (2003) LINEmediated retrotransposition of marked Alu sequences. Nat. Genet. 35, 41-48.

Emanuel, B. S., and Shaikh, T. H. (2001) Segmental duplications: An 'expanding' role in genomic instability and disease. Nat. Rev. Genet. 2, 791-800.

Englander, E. W., Wolffe, A. P., and Howard, B. H. (1993) Nucleosome interactions with a human Alu element - transcriptional repression and effects of template methylation. J. Biol. Chem. 268, 19565-19573.

Faulkner, G. J., Kimura, Y., Daub, C. O., Wani, S., Plessy, C., Irvine, K. M., Schroder, K., Cloonan, N., Steptoe, A. L., Lassmann, T., et al. (2009) The regulated retrotransposon transcriptome of mammalian cells. Nat. Genet. 41, 563571.

Feschotte, C. (2008) Transposable elements and the evolution of regulatory networks. Nat. Rev. Genet. 9, 397-405.

Feuchter, A. E., Freeman, J. D., and Mager, D. L. (1992) Strategy for detecting cellular transcripts promoted by human endogenous long terminal repeats: identification of a novel gene (CDC4L) with homology to yeast CDC4. Genomics 13, 1237-1246.

Fort, A., Hashimoto, K., Yamada, D., Salimullah, Md., Keya, C. A., Saxena, A., Bonetti, A., Voineagu, I., Bertin, N., Kratz, A., et al. (2014) Deep transcriptome profiling of mammalian stem cells supports a regulatory role for retrotransposons in pluripotency maintenance. Nat. Genet. 46, 558-566.

Frederick, L., Eley, G., Wang, X. Y., and James, C. D. (2000) Analysis of genomic rearrangements associated with EGRFvIII expression suggests involvement of Alu repeat elements. Neuro Oncol. 2, 159-163.

Gerber, A., O'Connell, M. A., and Keller, W. (1997) Two forms of human double-stranded RNA-specific editase 1 (hRED1) generated by the insertion of an Alu cassette. RNA 3, 453463.

Gombart, A. F., Saito, T., and Koeffler, H. P. (2009) Exaptation of an ancient Alu short interspersed element provides a highly conserved vitamin D-mediated innate immune response in humans and primates. BMC Genomics 10 , 
321.

Goodchild, N. L., Wilkinson, D. A., and Mager, D. L. (1992) A human endogenous long terminal repeat provides a polyadenylation signal to a novel, alternatively spliced transcript in normal placenta. Gene 121, 287-294.

Han, K., Sen, S. K., Wang, J., Callinan, P. A., Lee, J., Cordaux, R., Liang, P., and Batzer, M. A. (2005) Genomic rearrangements by LINE-1 insertion-mediated deletion in the human and chimpanzee lineages. Nucleic Acids Res. 33, 40404052 .

Han, K. D., Lee, J. N., Meyer, T. J., Remedios, P., Goodwin, L., and Batzer, M. A. (2008) L1 recombination-associated deletions generate human genomic variation. Proc. Natl. Acad. Sci. USA 105, 19366-19371.

Hanke, J. H., Hambor, J. E., and Kavathas, P. (1995) Repetitive $A l u$ elements form a cruciform structure that regulates the function of the human CD8 $\alpha \mathrm{T}$ cell-specific enhancer. J. Mol. Biol. 246, 63-73.

Harris, J. R. (1998) Placental endogenous retrovirus (ERV): structural, functional, and evolutionary significance. BioEssays 20, 307-316.

Hedges, D. J., and Batzer, M. A. (2005) From the margins of the genome: mobile elements shape primate evolution. BioEssays 27, 785-794.

Hellmann-Blumberg, U., Hintz, M. F. M., Gatewood, J. M., and Schmid, C. W. (1993) Developmental differences in methylation of human Alu repeats. Mol. Cell. Biol. 13, 4523-4530.

Herniou, E., Martin, J., Miller, K., Cook, J., Wilkinson, M., and Tristem, M. (1998) Retroviral diversity and distribution in vertebrates. J. Virol. 72, 5955-5966.

Hsu, D. W., Lin, M. J., Lee, T. L., Wen, S. C., Chen, X., and Shen, C. K. (1999) Two major forms of DNA (cytosine-5) methyltransferase in human somatic tissues. Proc. Natl. Acad. Sci. USA 96, 9751-9756.

Huh, J.-W., Ha, H.-S., Kim, D.-S., and Kim, H.-S. (2008a) Placenta-restricted expression of LTR-derived NOS3. Placenta 29, 602-608.

Huh, J.-W., Kim, D.-S., Ha, H.-S., Lee, J.-R., Kim, Y.-J., Ahn, K., Lee, S.-R., Chang, K.-T., and Kim, H.-S. (2008b) Cooperative exonization of MaLR and AluJo elements contributed an alternative promoter and novel splice variants of RNF19. Gene 424, 63-70.

Huh, J.-W., Kim, D.-S., Kang, D., Ha, H.-S., Ahn, K., Noh, Y.-N., Min, D., Chang, K.-T., and Kim, H.-S. (2008c) Transcriptional regulation of GSDML gene by antisense-oriented HERV-H LTR element. Arch. Virol. 153, 1201-1205.

Huh, J.-W., Kim, Y.-H., Lee, S.-R., Kim, H., Kim, D.-S., Kim, H.-S., Kang, H.-S., and Chang, K.-T. (2009) Gain of new exons and promoters by lineage-specific transposable elements-integration and conservation event on CHRM3 gene. Mol. Cells 28, 111-117.

Ichiyanagi, K. (2013) Epigenetic regulation of transcription and possible functions of mammalian short interspersed elements, SINEs. Genes Genet. Syst. 88, 19-29.

Ijdo, J. W., Baldini, A., Ward, D. C., Reeders, S. T., and Wells, R. A. (1991) Origin of human chromosome-2: an ancestral telomere-telomere fusion. Proc. Natl. Acad. Sci. USA 88, 9051-9055.

Jacobs, F. M. J., Greenberg, D., Nguyen, N., Haeussler, M., Ewing, A. D., Katzman, S., Paten, B., Salama, S. R., and Haussler, D. (2014) An evolutionary arms race between KRAB zinc-finger genes ZNF91/93 and SVA/L1 retrotransposons. Nature 516, 242-245.

Jacques, P. E., Jeyakani, J., and Bourque, G. (2013) The majority of primate-specific regulatory sequences are derived from transposable elements. PLoS Genet. 9, e1003504.

Johnson, R., Gamblin, R. J., Ooi, L., Bruce, A. W., Donaldson, I. J., Westhead, D. R., Wood, I. C., Jackson, R. M., and Buckley, N. J. (2006) Identification of the REST regulon reveals extensive transposable element-mediated binding site duplication. Nucleic Acids Res. 34, 3862-3877.

Johnson, R., Samuel, J., Ng, C. K. L., Jauch, R., Stanton, L. W., and Wood, I. C. (2009) Evolution of the vertebrate gene regulatory network controlled by the transcriptional repressor REST. Mol. Biol. Evol. 26, 1491-1507.

Jordan, I. K., Rogozin, I. B., Glazko, G. V., and Koonin, E. V. (2003) Origin of a substantial fraction of human regulatory sequences from transposable elements. Trends Genet. 19, 68-72.

Kapitonov, V. V., and Jurka, J. (1999) The long terminal repeat of an endogenous retrovirus induces alternative splicing and encodes an additional carboxy-terminal sequence in the human leptin receptor. J. Mol. Evol. 48, 248-251.

Karimi, M. M., Goyal, P., Maksakova, I. A., Bilenky, M., Leung, D., Tang, J. X., Shinkai, Y., Mager, D. L., Jones, S., Hirst, M., et al. (2011) DNA methylation and SETDB1/H3K9me3 regulate predominantly distinct sets of genes, retroelements, and chimeric transcripts in mESCs. Cell Stem Cell 8, 676-687.

Kazmierczak, B., Rosigkeit, J., Wanschura, S., Meyer-Bolte, K., Van de Ven, W., Kayser, K., Krieghoff, B., Kastendiek, H., Bartnitzke, S., and Bullerdiek, J. (1996) HMGI-C rearrangements as the molecular basis for the majority of pulmonary chondroid hamartomas: a survey of 30 tumors. Oncogene 12, 515-521.

Kehrer-Sawatzki, H., and Cooper, D. N. (2008) Molecular mechanisms of chromosomal rearrangement during primate evolution. Chromosome Res. 16, 41-56.

Kelley, D., and Rinn, J. (2012) Transposable elements reveal a stem cell-specific class of long noncoding RNAs. Genome Biol. 13, R107.

Kim, H. S. (2012) Genomic impact, chromosomal distribution and transcriptional regulation of HERV elements. Mol. Cells 33, 539-544.

Kim, P. M., Lam, H. Y. K., Urban, A. E., Korbel, J. O., Affourtit, J., Grubert, F., Chen, X. Y., Weissman, S., Snyder, M., and Gerstein, M. B. (2008) Analysis of copy number variants and segmental duplications in the human genome: Evidence for a change in the process of formation in recent evolutionary history. Genome Res. 18, 1865-1874.

Kim, Y.-J., Huh, J.-W., Kim, D.-S., Bae, M.-I., Lee, J.-R., Ha, H.-S., Ahn, K., Kim, T.-O., Song, G.-A., and Kim, H.-S. (2009) Molecular characterization of the DYX1C1 gene and its application as a cancer biomarker. J. Cancer Res. Clin. Oncol. 135, 265-270.

Kjellman, C., Sjögren, H.-O., Salford, L. G., and Widegren, B. (1999) HERV-F (XA34) is a full-length human endogenous retrovirus expressed in placental and fetal tissues. Gene 239, 99-107.

Kochanek, S., Renz, D., and Doerfler, W. (1993) DNA methylation in the Alu sequences of diploid and haploid primary human-cells. EMBO J. 12, 1141-1151.

Kondo-Iida, E., Kobayashi, K., Watanabe, M., Sasaki, J., Kumagai, T., Koide, H., Saito, K., Osawa, M., Nakamura, Y., and Toda, T. (1999) Novel mutations and genotype-phenotype relationships in 107 families with Fukuyama-type congenital muscular dystrophy (FCMD). Hum. Mol. Genet. 8, 2303-2309.

Kondo, Y., and Issa, J. P. J. (2003) Enrichment for histone H3 lysine 9 methylation at $A l u$ repeats in human cells. J. Biol. 
Chem. 278, 27658-27662.

Konkel, M. K., Walker, J. A., and Batzer, M. A. (2010) LINEs and SINEs of primate evolution. Evol. Anthropol. 19, 236249.

Korbel, J. O., Urban, A. E., Affourtit, J. P., Godwin, B., Grubert, F., Simons, J. F., Kim, P. M., Palejev, D., Carriero, N. J., $\mathrm{Du}, \mathrm{L}$., et al. (2007) Paired-end mapping reveals extensive structural variation in the human genome. Science 318, 420-426.

Kowalski, P. E., Freeman, J. D., and Mager, D. L. (1999) Intergenic splicing between a HERV-H endogenous retrovirus and two adjacent human genes. Genomics 57, 371-379.

Kunarso, G., Chia, N. Y., Jeyakani, J., Hwang, C., Lu, X. Y., Chan, Y. S., Ng, H. H., and Bourque, G. (2010) Transposable elements have rewired the core regulatory network of human embryonic stem cells. Nat. Genet. 42, 631-634.

Kuramochi-Miyagawa, S., Watanabe, T., Gotoh, K., Totoki, Y., Toyoda, A., Ikawa, M., Asada, N., Kojima, K., Yamaguchi, Y., Ijiri, T. W., et al. (2008) DNA methylation of retrotransposon genes is regulated by Piwi family members MILI and MIWI2 in murine fetal testes. Genes Dev. 22, 908-917.

Landry, J.-R., and Mager, D. L. (2003) Functional analysis of the endogenous retroviral promoter of the human endothelin B receptor gene. J. Virol. 77, 7459-7466.

Landry, J.-R., Rouhi, A., Medstrand, P., and Mager, D. L. (2002) The Opitz syndrome gene Mid1 is transcribed from a human endogenous retroviral promoter. Mol. Biol. Evol. 19, 19341942 .

Laperriere, D., Wang, T. T., White, J. H., and Mader, S. (2007) Widespread Alu repeat-driven expansion of consensus DR2 retinoic acid response elements during primate evolution. BMC Genomics 8, 23.

Lebedev, Y. B., Volik, S. V., Obradovic, D., Ermolaeva, O. D., Ashworth, L. K., Lennon, G. G., and Sverdlov, E. D. (1995) Physical mapping of sequences homologous to an endogenous retrovirus LTR on human-chromosome 19. Mol. Gen. Genet. 247, 742-748.

Lee, J.-R., Huh, J.-W., Kim, D.-S., Ha, H.-S., Ahn, K., Kim, Y.-J., Chang, K.-T., and Kim, H.-S. (2009) Lineage specific evolutionary events on SFTPB gene: Alu recombination-mediated deletion (ARMD), exonization, and alternative splicing events. Gene 435, 29-35.

Lee, J., Kim, Y., Mun, S., Kim, H. S., and Han, K. (2015) Identification of human -specific AluS elements through comparative genomics. Gene 555, 208-216.

Leib-Mosch, C., and Seifarth, W. (1995) Evolution and biological significance of human retroelements. Virus Genes 11, 133145.

Ling, J., Pi, W., Bollag, R., Zeng, S., Keskintepe, M., Saliman, H., Krantz, S., Whitney, B., and Tuan, D. (2002) The solitary long terminal repeats of ERV-9 endogenous retrovirus are conserved during primate evolution and possess enhancer activities in embryonic and hematopoietic cells. J. Virol. 76, 2410-2423.

Liu, A. Y., and Abraham, B. A. (1991) Subtractive cloning of a hybrid human endogenous retrovirus and calbindin gene in the prostate cell line PC3. Cancer Res. 51, 4107-4110.

Liu, G. E., Alkan, C., Jiang, L., Zhao, S., and Eichler, E. E. (2009) Comparative analysis of $A l u$ repeats in primate genomes. Genome Res. 19, 876-885.

Liu, S., Brind'Amour, J., Karimi, M. M., Shirane, K., Bogutz, A., Lefebvre, L., Sasaki, H., Shinkai, Y., and Lorincz, M. C. (2014) Setdb1 is required for germline development and silencing of H3K9me3-marked endogenous retroviruses in primordial germ cells. Genes Dev. 28, 2041-2055.
Liu, W. M., and Schmid, C. W. (1993) Proposed roles for DNA methylation in $A l u$ transcriptional repression and mutational inactivation. Nucleic Acids Res. 21, 1351-1359.

Lower, R., Lower, J., and Kurth, R. (1996) The viruses in all of us: Characteristics and biological significance of human endogenous retrovirus sequences. Proc. Natl. Acad. Sci. USA 93, 5177-5184.

Lunyak, V. V., Prefontaine, G. G., Nunez, E., Cramer, T., Ju, B. G., Ohgi, K. A., Hutt, K., Roy, R., Garcia-Diaz, A., Zhu, X. Y., et al. (2007) Developmentally regulated activation of a SINE B2 repeat as a domain boundary in organogenesis. Science 317, 248-251.

Lynch, V. J., Leclerc, R. D., May, G., and Wagner, G. P. (2011) Transposon-mediated rewiring of gene regulatory networks contributed to the evolution of pregnancy in mammals. Nat. Genet. 43, 1154-1159.

Mager, D. L., and Freeman, J. D. (1995) HERV-H endogenous retroviruses - presence in the New-World branch but amplification in the Old-World primate lineage. Virology 213, 395-404.

Mager, D. L., Hunter, D. G., Schertzer, M., and Freeman, J. D. (1999) Endogenous retroviruses provide the primary polyadenylation signal for two new human genes (HHLA2 and HHLA3). Genomics 59, 255-263.

Malik, H. S., and Eickbush, T. H. (2001) Phylogenetic analysis of ribonuclease $\mathrm{H}$ domains suggests a late, chimeric origin of LTR retrotransposable elements and retroviruses. Genome Res. 11, 1187-1197.

Martens, J. H. A., O’Sullivan, R. J., Braunschweig, U., Opravil, S., Radolf, M., Steinlein, P., and Jenuwein, T. (2005) The profile of repeat-associated histone lysine methylation states in the mouse epigenome. EMBO J. 24, 800-812.

Matsui, T., Leung, D., Miyashita, H., Maksakova, I. A., Miyachi, H., Kimura, H., Tachibana, M., Lorincz, M. C., and Shinkai, Y. (2010) Proviral silencing in embryonic stem cells requires the histone methyltransferase ESET. Nature 464, 927931.

Medstrand, P., and Mager, D. L. (1998) Human-specific integrations of the HERV-K endogenous retrovirus family. J. Virol. 72, 9782-9787.

Medstrand, P., Landry, J.-R., and Mager, D. L. (2001) Long terminal repeats are used as alternative promoters for the endothelin B receptor and apolipoprotein CI genes in humans. J. Biol. Chem. 276, 1896-1903.

Meischl, C., de Boer, M., Ahlin, A., and Roos, D. (2000) A new exon created by intronic insertion of a rearranged LINE-1 element as the cause of chronic granulomatous disease. Eur. J. Hum. Genet. 8, 697-703.

Mihovilovic, M., Mai, Y., Herbstreith, M., Rubboli, F., Tarroni, P., Clementi, F., and Roses, A. D. (1993) Splicing of an antisense Alu sequence generates a coding sequence variant for the $\alpha-3$ subunit of a neuronal acetylcholine receptor. Biochem. Biophys. Res. Commun. 197, 137-144.

Miki, Y., Nishisho, I., Horii, A., Miyoshi, Y., Utsunomiya, J., Kinzler, K. W., Vogelstein, B., and Nakamura, Y. (1992) Disruption of the $A P C$ gene by a retrotransposal insertion of L1 sequence in a colon cancer. Cancer Res. 52, 643-645.

Mikkelsen, T. S., Ku, M. C., Jaffe, D. B., Issac, B., Lieberman, E., Giannoukos, G., Alvarez, P., Brockman, W., Kim, T. K., Koche, R. P., et al. (2007) Genome-wide maps of chromatin state in pluripotent and lineage-committed cells. Nature 448, 553-560.

Moses, A. M., Pollard, D. A., Nix, D. A., Iyer, V. N., Li, X. Y., Biggin, M. D., and Eisen, M. B. (2006) Large-scale turnover of functional transcription factor binding sites in Drosophila. 
PLOS Comput. Biol. 2, 1219-1231.

Mukherjee, S., Mukhopadhyay, A., Banerjee, D., Chandak, G. R., and Ray, K. (2004) Molecular pathology of haemophilia B: identification of five novel mutations including a LINE 1 insertion in Indian patients. Haemophilia 10, 259-263.

Mullersman, J. E., and Pfeffer, L. M. (1995) An Alu cassette in the cytoplasmic domain of an interferon receptor subunit. J. Interf. Cytok. Res. 15, 815-817.

Murnane, J. P., and Morales, J. F. (1995) Use of a mammalian interspersed repetitive (MIR) element in the coding and processing sequences of mammalian genes. Nucleic Acids Res. 23, 2837-2839.

Myers, J. S., Vincent, B. J., Udall, H., Watkins, W. S., Morrish, T. A., Kilroy, G. E., Swergold, G. D., Henke, J., Henke, L., Moran, J. V., et al. (2002) A comprehensive analysis of recently integrated human Ta L1 elements. Am. J. Hum. Genet. 71, 312-326.

Narita, N., Nishio, H., Kitoh, Y., Ishikawa, Y., Ishikawa, Y., Minami, R., Nakamura, H., and Matsuo, M. (1993) Insertion of a 5' truncated L1 element into the 3' end of exon-44 of the dystrophin gene resulted in skipping of the exon during splicing in a case of Duchenne muscular-dystrophy. J. Clin. Invest. 91, 1862-1867.

Nickerson, E., and Nelson, D. L. (1998) Molecular definition of pericentric inversion breakpoints occurring during the evolution of humans and chimpanzees. Genomics 50, 368372.

Nishihara, H., Smit, A. F. A., and Okada, N. (2006) Functional noncoding sequences derived from SINEs in the mammalian genome. Genome Res. 16, 864-874.

Odom, D. T., Dowell, R. D., Jacobsen, E. S., Gordon, W., Danford, T. W., MacIsaac, K. D., Rolfe, P. A., Conboy, C. M., Gifford, D. K., and Fraenkel, E. (2007) Tissue-specific transcriptional regulation has diverged significantly between human and mouse. Nat. Genet. 39, 730-732.

Ohnuki, M., Tanabe, K., Sutou, K., Teramoto, I., Sawamura, Y., Narita, M., Nakamura, M., Tokunaga, Y., Nakamura, M., Watanabe, A., et al. (2014) Dynamic regulation of human endogenous retroviruses mediates factor-induced reprogramming and differentiation potential. Proc. Natl. Acad. Sci. USA 111, 12426-12431.

Ohshima, K., Hattori, M., Yada, T., Gojobori, T., Sakaki, Y., and Okada, N. (2003) Whole-geneome screening indicates a possible burst of formation of processed pseudogenes and Alu repeats by particular L1 subfamilies in ancestral primates. Genome Biol. 4, R74.

Okada, N. (1991) SINEs: Short interspersed repeated elements of the eukaryotic genome. Trends Ecol. Evol. 6, 358-361.

Oler, A. J., Alla, R. K., Roberts, D. N., Wong, A., Hollenhorst, P. C., Chandler, K. J., Cassiday, P. A., Nelson, C. A., Hagedorn, C. H., Graves, B. J., et al. (2010) Human RNA polymerase III transcriptomes and relationships to Pol II promoter chromatin and enhancer-binding factors. Nat. Struct. Mol. Biol. 17, 620-628.

Oliver, K. R., and Greene, W. K. (2009) Transposable elements: powerful facilitators of evolution. BioEssays 31, 703-714.

Oliver, K. R., and Greene, W. K. (2011) Mobile DNA and the TEThrust hypothesis: supporting evidence from the primates. Mob. DNA 2, 8.

Oliviero, S., and Monaci, P. (1988) RNA polymerase III promoter elements enhance transcription of RNA polymerase II genes. Nucleic Acids Res. 16, 1285-1293.

Ostertag, E. M., Goodier, J. L., Zhang, Y., and Kazazian Jr, H. H. (2003) SVA elements are nonautonomous retrotransposons that cause disease in humans. Am. J. Hum. Genet. 73,
1444-1451.

Patience, C., Wilkinson, D. A., and Weiss, R. A. (1997) Our retroviral heritage. Trends Genet. 13, 116-120.

Perron, H., Garson, J. A., Bedin, F., Beseme, F., ParanhosBaccala, G., Komurian-Pradel, F., Mallet, F., Tuke, P. W., Voisset, C., Blond, J. L., et al. (1997) Molecular identification of a novel retrovirus repeatedly isolated from patients with multiple sclerosis. Proc. Natl. Acad. Sci. USA 94, 7583-7588.

Polak, P., and Domany, E. (2006) Alu elements contain many binding sites for transcription factors and may play a role in regulation of developmental processes. BMC Genomics 7, 133.

Prufer, K., Munch, K., Hellmann, I., Akagi, K., Miller, J. R., Walenz, B., Koren, S., Sutton, G., Kodira, C., Winer, R., et al. (2012) The bonobo genome compared with the chimpanzee and human genomes. Nature 486, 527-531.

Reik, W., Dean, W., and Walter, J. (2001) Epigenetic reprogramming in mammalian development. Science 293, 10891093.

Romanish, M. T., Lock, W. M., van de Lagemaat, L. N., Dunn, C. A., and Mager, D. L. (2007) Repeated recruitment of LTR retrotransposons as promoters by the anti-apoptotic locus NAIP during mammalian evolution. PLoS Genet. 3, e10.

Romano, C. M., Ramalho, R. F., and Zanotto, P. M. de A. (2006) Tempo and mode of ERV-K evolution in human and chimpanzee genoems. Arch. Virol. 151, 2215-2228.

Samuelson, L. C. (1996) Transgenic approaches to salivary gland research. Annu. Rev. Physiol. 58, 209-229.

Santangelo, A. M., de Souza, F. S. J., Franchini, L. F., Bumaschny, V. F., Low, M. J., and Rubinstein, M. (2007) Ancient exaptation of a CORE-SINE retroposon into a highly conserved mammalian neuronal enhancer of the proopiomelanocortin gene. PLoS Genet. 3, e166.

Sasaki, H., and Matsui, Y. (2008) Epigenetic events in mammalian germ-cell development: reprogramming and beyond. Nat. Rev. Genet. 9, 129-140.

Sasaki, T., Nishihara, H., Hirakawa, M., Fujimura, K., Tanaka, M., Kokubo, N., Kimura-Yoshida, C., Matsuo, I., Sumiyama, K., Saitou, N., et al. (2008) Possible involvement of SINEs in mammalian-specific brain formation. Proc. Natl. Acad. Sci. USA 105, 4220-4225.

Schmidt, D., Schwalie, P. C., Wilson, M. D., Ballester, B., Gonçalves, Â., Kutter, C., Brown, G. D., Marshall, A., Flicek, P., and Odom, D. T. (2012) Waves of retrotransposon expansion remodel genome organization and CTCF binding in multiple mammalian lineages. Cell 148, 335-348.

Schulte, A. M., Malerczyk, C., Cabal-Manzano, R., Gajarsa, J. J., List, H.-J., Riegel, A. T., and Wellstein, A. (2000) Influence of the human endogenous retrovirus-like element HERV-E. PTN on the expression of growth factor pleiotrophin: a critical role of a retroviral Sp1-binding site. Oncogene 19, 3988-3998.

Schwahn, U., Lenzner, S., Dong, J., Feil, S., Hinzmann, B., van Duijnhoven, G., Kirschner, R., Hemberger, M., Bergen, A. A. B., Rosenberg, T., et al. (1998) Positional cloning of the gene for X-linked retinitis pigmentosa 2. Nat. Genet. 19, 327-332.

Sen, S. K., Han, K., Wang, J., Lee, J., Wang, H., Callinan, P. A., Dyer, M., Cordaux, R., Liang, P., and Batzer, M. A. (2006) Human genomic deletions mediated by recombination between Alu elements. Am. J. Hum. Genet. 79, 41-53.

Shen, M. R., Batzer, M. A., and Deininger, P. L. (1991) Evolution of the master Alu gene(s). J. Mol. Evol. 33, 311-320.

Simpson, G. R., Patience, C., Lower, R., Tonjes, R. R., Moore, H. D. M., Weiss, R. A., and Boyd, M. T. (1996) Endogenous D- 
type (HERV-K) related sequences are packaged into retroviral particles in the placenta and possess open reading frames for reverse transcriptase. Virology 222, 451-456.

Sin, H.-S., Huh, J.-W., Kim, D.-S., Kim, T.-H., Ha, H.-S., Kim, W.-Y., Park, H.-K., Kim, C.-M., and Kim, H.-S. (2006) Endogenous retrovirus-related sequences provide an alternative transcript of $M C J$ genes in human tissues and cancer cells. Genes Genet. Syst. 81, 333-339.

Sin, H. S., Huh, J. W., Kim, W. Y., Kim, D. S, Ahn, K., Ha, H. S., and Kim, H. S. (2007) Long terminal repeats of human endogenous retrovirus $\mathrm{H}$ family provide alternative polyadenylation signals to NADSYN1 gene. Kor. J. Genet. 29, 395-401.

Siomi, M. C., Sato, K., Pezic, D., and Aravin, A. A. (2011) PIWIinteracting small RNAs: the vanguard of genome defence. Nat. Rev. Mol. Cell Biol. 12, 246-258.

Slotkin, R. K., and Martienssen, R. (2007) Transposable elements and the epigenetic regulation of the genome. Nat. Rev. Genet. 8, 272-285.

Smit, A. F. A., and Riggs, A. D. (1996) Tiggers and other DNA transposon fossils in the human genome. Proc. Natl. Acad. Sci. USA 93, 1443-1448.

Smit, A. F. A., Hubley, R., and Green, P. (1996-2010) RepeatMasker Open - $3.0<\mathrm{http}: / /$ www.repeatmasker.org $>$

Sundaram, V., Cheng, Y., Ma, Z., Li, D., Xing, X., Edge, P., Snyder, M. P., and Wang, T. (2014) Widespread contribution of transposable elements to the innovation of gene regulatory networks. Genome Res. 24, 1963-1976.

Sverdlov, E. D. (1998) Perpetually mobile footprints of ancient infections in human genome. FEBS Lett. 428, 1-6.

Sverdlov, E. D. (2000) Retroviruses and primate evolution. BioEssays 22, 161-171.

Svineng, G., Fassler, R., and Johansson, S. (1998) Identification of $\beta 1 \mathrm{C}-2$, a novel variant of the integrin $\beta 1$ subunit generated by utilization of an alternative splice acceptor site in exon C. Biochem. J. 330, 1255-1263.

Tan, S., Nishi, M., Ohtsuka, T., Matsui, T., Takemoto, K., Kamio-Miura, A., Aburatani, H., Shinkai, Y., and Kageyama, R. (2012) Essential roles of the histone methyl- transferase ESET in the epigenetic control of neural progenitor cells during development. Development 139, 38063816 .

Tsumura, A., Hayakawa, T., Kumaki, Y., Takebayashi, S., Sakaue, M., Matsuoka, C., Shimotohno, K., Ishikawa, F., Li, E., Ueda, H. R., et al. (2006) Maintenance of self-renewal ability of mouse embryonic stem cells in the absence of DNA methyltransferases Dnmt1, Dnmt3a and Dnmt3b. Genes Cells 11, 805-814.

Ullu, E., and Tschudi, C. (1984) Alu sequences are processed 7SL RNA genes. Nature 312, 171-172.

Walsh, C. P., Chaillet, J. R., and Bestor, T. H. (1998) Transcription of IAP endogenous retroviruses is constrained by cytosine methylation. Nat. Genet. 20, 116-117.

Wang, H., Xing, J., Grover, D., Hedges, D. J., Han, K., Walker, J. A., and Batzer, M. A. (2005) SVA elements: a hominidspecific retroposon family. J. Mol. Biol. 354, 994-1007.

Wang, T., Zeng, J., Lowe, C. B., Sellers, R. G., Salama, S. R., Yang, M., Burgess, S. M., Brachmann, R. K., and Haussler, D. (2007) Species-specific endogenous retroviruses shape the transcriptional network of the human tumor suppressor protein p53. Proc. Natl. Acad. Sci. USA 104, 18613-18618.

Watanabe, T., Chuma, S., Yamamoto, Y., Kuramochi-Miyagawa, S., Totoki, Y., Toyoda, A., Hoki, Y., Fujiyama, A., Shibata, T., Sado, T., et al. (2011) MITOPLD is a mitochondrial protein essential for nuage formation and piRNA biogenesis in the mouse germline. Dev. Cell 20, 364-375.

Xie, H. H., Wang, M., Bonaldo, M. D., Smith, C., Rajaram, V., Goldman, S., Tomita, T., and Soares, M. B. (2009) Highthroughput sequence-based epigenomic analysis of Alu repeats in human cerebellum. Nucleic Acids Res. 37, 4331-4340.

Zhao, H., and Bourque, G. (2009) Recovering genome rearrangements in the mammalian phylogeny. Genome Res. 19, 934-942.

Zietkiewicz, E., Richer, C., Sinnett, D., and Labuda, D. (1998) Monophyletic origin of Alu elements in primates. J. Mol. Evol. 47, 172-182. 